\title{
Synthesis of Indoles and Pyrroles Utilizing Iridium Carbenes Generated from Sulfoxonium Ylides
}

\author{
Janakiram Vaitla, ${ }^{\star}$ Annette Bayer, and Kathrin H. Hopmann
}

\begin{abstract}
Metal-carbenes can undergo a myriad of synthetic transformations. Sulfur ylides are potential safe precursors of metalcarbenes. Herein, we report the first cascade reactions employing sulfoxonium ylide-derived carbenoids and providing efficient and regioselective syntheses of indoles and pyrroles. The tandem action of iridium and Bronsted acid catalysts allows quick assembly of the heterocycles from unmodified anilines or easily accessible enamines, under microwave irradiation. The key mechanistic steps comprise the catalytic transformation of sulfoxonium ylides to iridium-carbene complexes, followed by $\mathrm{N}-\mathrm{H}$ or $\mathrm{C}-\mathrm{H}$ functionalization of anilines or enamines, respectively, and a final acid-catalysed cyclisation. The present method is successfully applied to the synthesis of the densely functionalized pyrrole subunit of Atorvastatin.
\end{abstract}

Sulfur (sulfonium and sulfoxonium) ylides are versatile synthetic precursors for a diverse range of chemical transformations ${ }^{[1]}$, e. g. they are widely used as methylene synthons in the formation of small rings such as epoxides, aziridines, and cyclopropanes from electrophilic substrates like aldehydes, imines, and enones. Recently, cycloadditions of sulfur ylides to a variety of electrophilic metal ( $\mathrm{Pd}, \mathrm{Fe}, \mathrm{Cu}, \mathrm{Rh}$, or $\mathrm{Au}$ ) associated intermediates have been explored for synthesis of heterocycles (Scheme 1; Type I). ${ }^{[2]}$

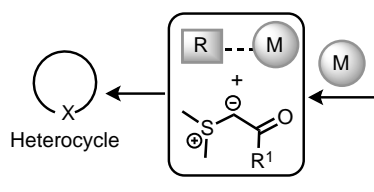

Type I

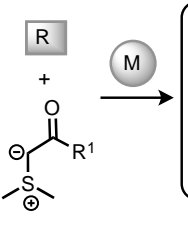

$R=$ Reactant

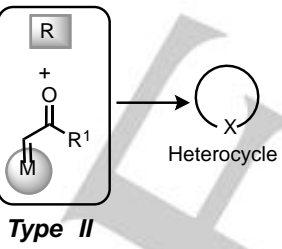

M $=$ Metal complex synthesis via a metal-associated Scheme 1. Sulfur ylide-based heterocycle synthesis via a meta
intermediate (Type I) or via a metal-carbene complex (Type II).

Sulfur ylides can also function as precursors for transition metal-

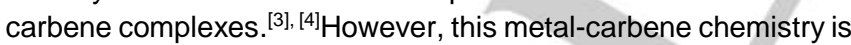
currently limited to insertion of $\mathrm{X}-\mathrm{H}(\mathrm{X}=\mathrm{N}, \mathrm{O}, \mathrm{S})$ bonds and cyclopropanation reactions. ${ }^{[5]}$ Development of sulfur ylide-based metal carbene chemistry for a wider range of applications is highly desirable ${ }^{[6]}$ as it can offer some advantages over diazo carbenes. Large scale synthesis using diazo compounds can be

[*] Dr. J. Vaitla, Dr. K. H. Hopmann Department of Chemistry and Centre for Theoretical and Computational Chemistry (CTCC) University of Tromsø, 9037 Tromsø, (Norway) E-mail: janakiram.vaitla@uit.no Dr. A. Bayer, Department of Chemistry, University of Tromsø, 9037 Troms $\varnothing$, (Norway)

${ }^{\left.{ }^{\star *}\right]}$ This work has received support from the Research Council of Norway (Grant No.231706)

Supporting information for this article is given via a link at the end of the document. challenging, due to safety issues resulting from rapid exotherm reactions. ${ }^{[7]}$ Sulfoxonium ylides are safer to synthesize and give crystalline, bench-stable compounds that can serve as practical substitutes of diazo compounds in metal-carbene reactions. ${ }^{[5 \mathrm{e}]}$ However, unlike diazo carbenes, sulfoxonium ylide-based carbenes have not yet been explored in cascade transformations. ${ }^{[8]}$ In light of this, we became interested in studying the potential of metal-catalyzed sulfur ylide chemistry (Scheme 1; Type II) in a cascade approach for synthesis of heteroaromatic compounds such as indoles and pyrroles.

The indole moiety is found in many natural products, pharmaceuticals, and agrochemicals, ${ }^{[9]}$ and numerous methods for the synthesis of the indole scaffold have been developed. Most of the reported methods for indole syntheses require modified anilines such as $\mathrm{N}$-substituted aniline derivatives or ortho functionalized anilines, ${ }^{[10]}$ including an approach employing $N$ (ortho-chloromethyl)aryl amides and sulfur ylides as methylene synthons. ${ }^{[11]}$ In 1881, Möhlau reported the synthesis of indoles from unmodified anilines with ortho-haloketones. ${ }^{[12]}$ This reaction has received little attention, perhaps due to its poor regioselectivity, low yields, harsh reaction conditions and the frequent need for a two-step process. ${ }^{[13]}$ An efficient procedure for conversion of simple anilines to substituted indoles in one step is lacking.

Herein, we report a highly regioselective one-step iridiumcatalyzed indole synthesis from unmodified anilines and sulfur ylides (Scheme 2).

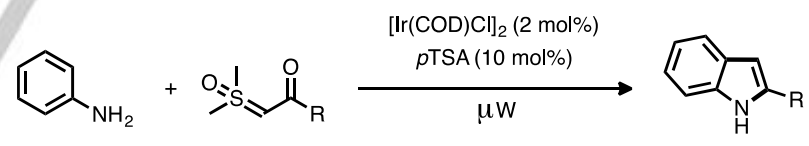

Scheme 2. Sulfur ylide-derived metal carbenes in indole synthesis.

Initially, we investigated the microwave irradiation of aniline (2 equiv.) with ylide $2 \mathbf{a}$ (1 equiv.) in the presence of $[\mathrm{Ir}(\mathrm{COD}) \mathrm{Cl}]_{2}(10$ mol\%) in dichloroethane at $80{ }^{\circ} \mathrm{C}$ for $45 \mathrm{~min}$. Interestingly, the reaction afforded a small amount of unprecedented 2-substituted indole $4 a$ (5\% yield) along with the expected $\mathrm{N}$-alkylated aniline $3 \mathbf{a}(73 \%$ yield) (Table 1, entry 1$)$. Other transition metal $(\mathrm{Ru}, \mathrm{Rh})$ catalysts afforded low yields of the $\mathrm{N}$-alkylated product $3 \mathbf{a}$ (Table 1, entries 2-4). An increased amount of indole 4a (12\%) was observed when the iridium catalyzed reaction was performed at $140{ }^{\circ} \mathrm{C}$ in toluene as a solvent (Table 1 , entry 5 ). No reaction is observed in absence of iridium catalyst (Table 1, entry 6 ), which is a noticeable indication of the stability of ylide 2 a under microwave heating conditions $\left(140{ }^{\circ} \mathrm{C}\right)$. For comparison, adiazoketones undergo either decomposition or Wolf rearrangement at high temperatures, which may give possible side reactions. ${ }^{[14]}$ Using $\mathrm{TfOH}$ (20 mol\%), PPA (20 mol\%), or PTSA (30 mol\%) along with the iridium-catalyst led to a mixture of 2- and 3-substituted indoles (Table 1, entry 7-9). The formation of 3-substituted indole $5 \mathrm{a}$ can be explained by a Friedel-Craft type 
reaction of the $\mathrm{N}$-alkylated aniline $\mathbf{3 a}$ under increased acid concentration. ${ }^{[15]}$

Table 1. Optimization of the reaction conditions ${ }^{[a]}$

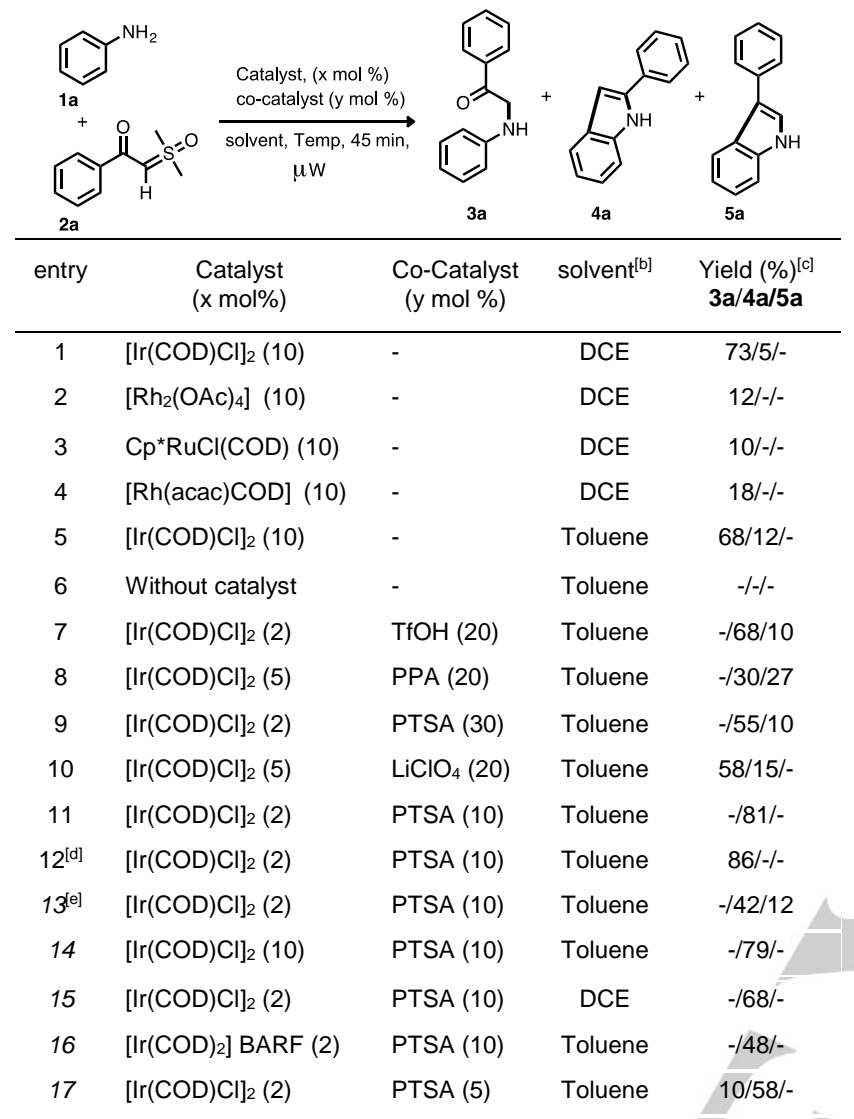

[a] All reactions were carried out in $2 \mathrm{mmol}$ of $\mathbf{1 a}$ and $1 \mathrm{mmol}$ of $\mathbf{2 a}$ in $3.0 \mathrm{~mL}$ solvent unless otherwise specified. ${ }^{[b]}$ Reaction carried out at $80^{\circ} \mathrm{C}$ for DCE solvent and $140{ }^{\circ} \mathrm{C}$ for toluene solvent. [c] Yield of the isolated product [d] Reaction carried out at room temperature without microwave irradiation for $20 \mathrm{~h}$ [e] Reaction carried out using $1 \mathrm{mmol}$ of $1 \mathrm{a}$ and $1 \mathrm{mmol}$ of $\mathbf{2 a}$. TfOH= Triflic acid, PPA $=$ Polyphosphoric acid, PTSA $=p$-Toluenesulfonic acid

Gratifyingly, decreasing the PTSA loading from 30 to $10 \mathrm{~mol}$ $\%$ afforded selectively 2 -substituted indole $4 a$ in $>80 \%$ isolated yield (entry 11). The corresponding reaction at $110{ }^{\circ} \mathrm{C}$ without microwave irradiation for $16 \mathrm{~h}$ afforded $4 \mathrm{a}$ at comparable yield. Partial formation of $\mathbf{5 a}$ was also noticed when decreasing the aniline concentration from 2 equiv. to 1 equiv. (entry 13).

With the optimized reaction conditions at hand (Table 1, entry 11), we then examined the substrate scope of this reaction (Scheme 3). A series of sulfoxonium ylide substrates having electron-donating and-withdrawing groups and halo substituents on the benzene ring of $\mathbf{2}$ underwent smooth cyclization, resulting in the formation of the indole products 4 in moderate to good yields. When a nitro group was introduced on the benzene ring of ylide 2, the present reaction conditions gave poor yields of the corresponding indole $4 \mathrm{I}$. This problem was addressed by carrying out the reaction in a mixed solvent of toluene/DMF (3:1), improving the yield of indole $4 \mathrm{I}$ up to $54 \%{ }^{[16]}$ The aliphatic ylide $2 q\left(R^{\prime}=M e\right)$ furnished low yields $(12 \%)$ of indole $\mathbf{4 q}$. When examining the scope of aniline derivatives, we found that electron donating substituents such as methyl, methoxy as well as methylthio groups on the aniline ring were well tolerated. The polycyclic indole $\mathbf{4 p}$ was obtained from 1 -aminonaphtalene in $72 \%$ yield. In the case of non-symmetric 3,4- (methylenedioxy)aniline 1d, the reaction was highly regioselective and only one isomer $\mathbf{4 d}$ was obtained in $73 \%$ yield (Scheme 3 ).
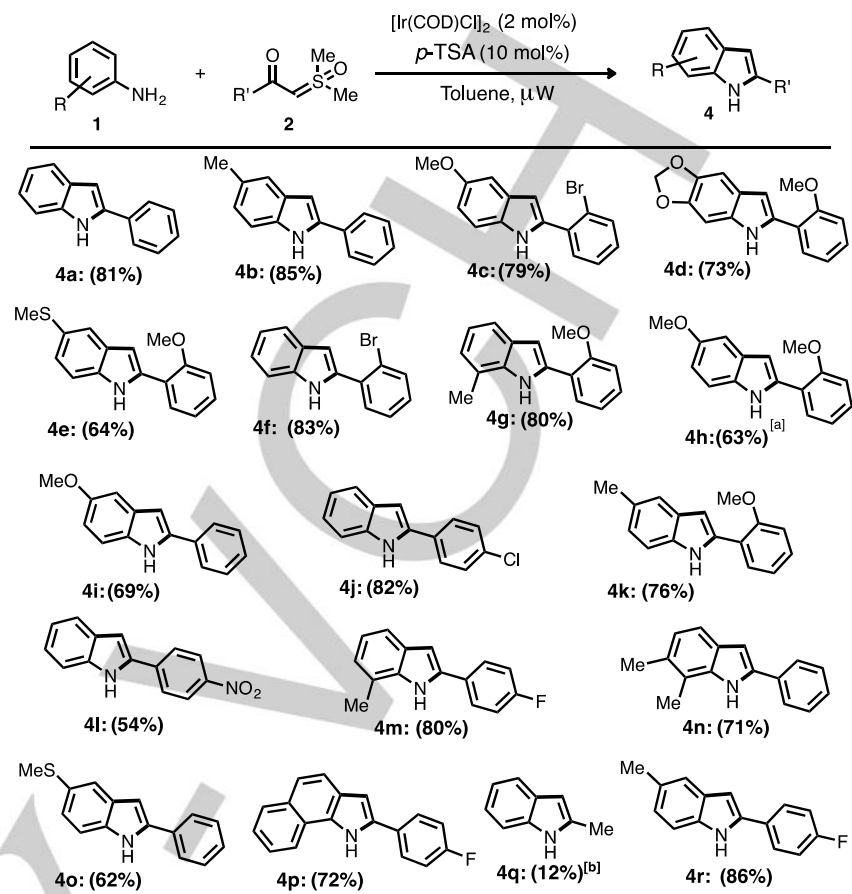

Scheme 3. Scope of iridium-catalyzed synthesis of indoles. General conditions: $1(2 \mathrm{mmol}), 2(1 \mathrm{mmol})$, toluene $(3.0 \mathrm{~mL})$. Yields of isolated product are given. [a] $15 \%$ indole regioisomer $\mathbf{5 h}$ is observed. ${ }^{[b]} 40 \%$ of $N$-alkylated product $\mathbf{3 q}$ observed.

When halogen atoms and electron withdrawing groups were introduced on the aniline ring, the reaction did not afford the indole products, but instead we observed the corresponding $\mathrm{N}$-alkylated anilines 3, showing that electron poor aniline derivatives did not cyclize to the indoles. ${ }^{[17]}$

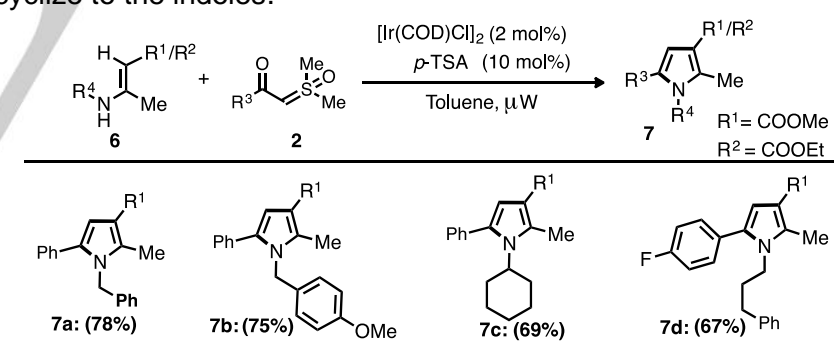

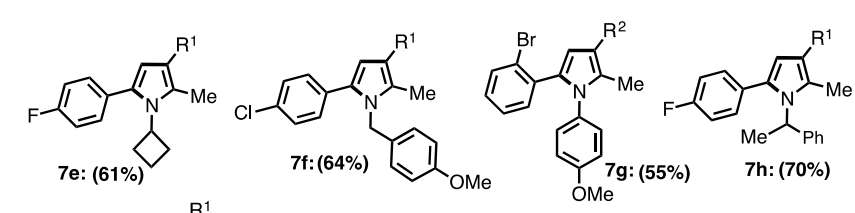

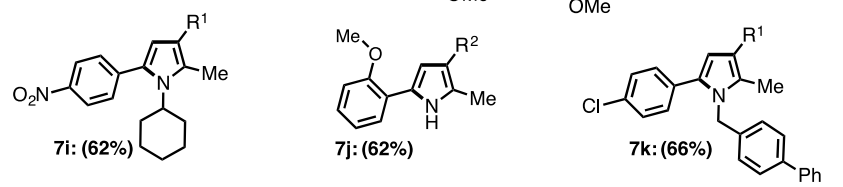

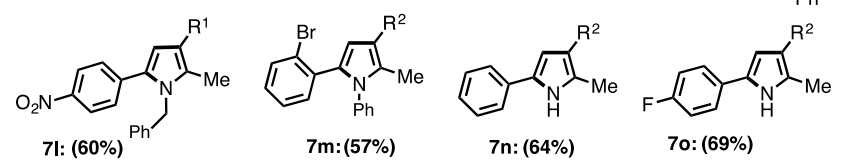

Scheme 4. Scope of iridium-catalyzed synthesis of pyrroles. General conditions: $6(2 \mathrm{mmol}), 2(1 \mathrm{mmol}),[\mathrm{Ir}(\mathrm{COD}) \mathrm{Cl}]_{2}(2 \mathrm{~mol} \%), p \mathrm{TSA}(10.0 \mathrm{~mol} \%)$, Toluene $(3.0 \mathrm{~mL}), 140^{\circ} \mathrm{C}, 45 \mathrm{~min}$ under MW irradiation. Yields of isolated product are given. 
Next, we envisioned that analogously to the indole synthesis, pyrroles ${ }^{[18]}$ may be formed from the reaction of a sulfoxonium ylide with a $\beta$-enamino ester. Treatment of ylides 2 with $\beta$-enamino esters 6 in the presence of $[\operatorname{lr}(\mathrm{COD}) \mathrm{Cl}]_{2}(2 \mathrm{~mol} \%)$ and $p$-TSA $(10 \mathrm{~mol} \%)$ in toluene at $140{ }^{\circ} \mathrm{C}$ under microwave irradiation gave the pyrroles 7 (Scheme 4). A series of electronically diverse ylides (2) underwent smooth cyclisation with various $\beta$-enamino esters $6\left(R^{4}=\right.$ benzylic, aliphatic or cyclic, aromatic) to provide the corresponding pyrrole derivatives in moderate to good yields (55-78\%). Additionally, we achieved the one pot three component synthesis of pyrroles (Scheme 5) using in situ generated $\beta$-enaminoester (from amine (8) and $\beta$ ketoesters (9)) with sulfoxonium ylide. ${ }^{[16]}$

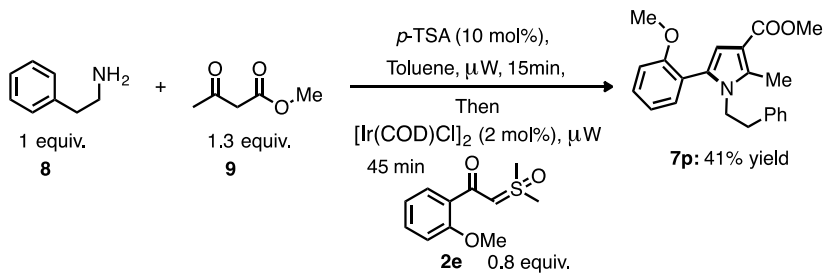

Scheme 5. One pot reaction for pyrrole synthesis.

The applicability of our method was demonstrated by the synthesis of the pyrrole subunit of Atorvastatin (Lipitor) 12 (Scheme 6), the world's largest selling cholesterol-lowering drug in therapeutic use. ${ }^{[19]}$ The cyclization of $\beta$-enamino amide $\mathbf{1 0}$ with sulfoxonium ylide 11 in the presence of $[\operatorname{Ir}(\mathrm{COD}) \mathrm{Cl}]_{2}(2 \mathrm{~mol} \%)$ and p-TSA (10 mol\%) gave tetra substituted pyrrole ${ }^{[20]} 12$ in 58\% yield.

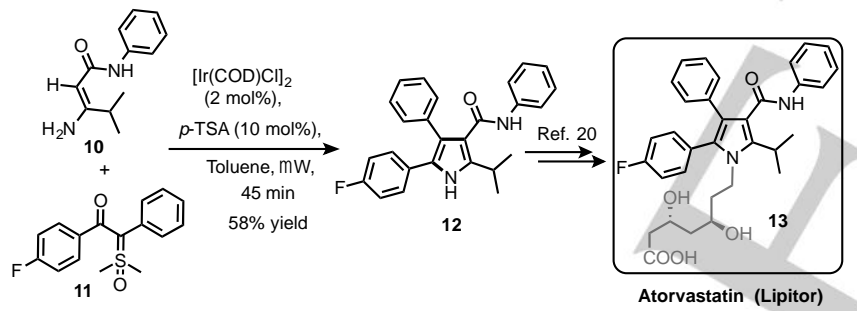

Scheme 6. Synthesis of the pyrrole subunit of Atorvastatin 12.

To gain insight into the reaction mechanisms, a series of control experiments were set up (Scheme 7). First, treating the iridium catalyst with ylide $\mathbf{2}$ in absence of aniline or $\beta$-enamino ester resulted in dimerization of ylides. ${ }^{\left[5 b,{ }^{16]}\right.}$ Next, the reaction of ylide 2 and 4-methoxy aniline was evaluated in absence of the Bronsted acid co-catalyst under microwave irradiation resulting in $\mathrm{N}-\mathrm{H}$ insertion of the carbene to afford $\mathbf{3 b}$. Interestingly, replacing $1 \mathbf{a}^{\prime}$ with $\beta$-enaminoester $\mathbf{6} \mathbf{a}^{\prime}$ under the same reaction conditions resulted in selective $\mathrm{C}-\mathrm{H}$ functionalization in presence of a free $\mathrm{N}$ $\mathrm{H}$ group, giving $14 \mathrm{a}$ in $88 \%$ yield. Previous studies involving other metal carbenes have reported unselective $\mathrm{N}$ and $\mathrm{C}$ attack of acyclic $\beta$-enaminoesters, resulting in mixtures of pyrroles. ${ }^{[21]} \mathrm{Ir}$ carbenoids generated from sulfoxonium ylides might be less reactive but more selective compared to other metal carbenes. ${ }^{[5 b]}$ In order to evaluate the role of the acid, $\mathbf{3} \mathbf{b}$ (1 equiv.) and aniline (1.2 equiv.) were reacted under acid-catalyzed conditions to afford a mixture of 2-aryl indoles $\mathbf{4 i}$ and $\mathbf{4 a}$ in a 1:10 ratio, whereas reaction of $\mathbf{3 b}$ (1 equiv.) with 1a' (1.2 equiv.) resulted in $\mathbf{4} \mathbf{i}$ in $81 \%$ yield. This reaction resembles a Bischler-Möhlau indole synthesis, but the latter normally gives mixtures of regioisomers (4 and 5 ) due to a competition between imine formation and a
Friedel-Craft type reaction [13a] and is performed with an excess of base in order to trap the in situ generated acid. In the new method described here, the regioselectivity can be controlled through catalytic amounts of acid to give exclusively 2 -substituted indoles (Table 1).

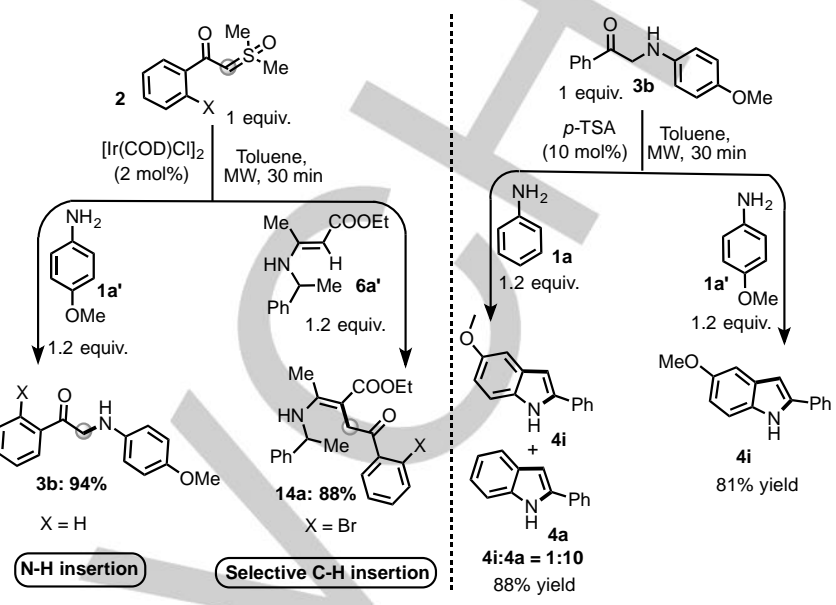

Scheme 7. Mechanistic investigations.

From these observations ${ }^{[16]}$ (Scheme 7) and literature precedents, ${ }^{[5]}$ a plausible mechanism is shown in Scheme 8 . The activation of the sulfoxonium ylide 2 using $\operatorname{Ir}(\mathrm{I})$ generates the iridium carbene complex $\mathbf{A}$. This carbene is trapped by aniline to give 3, which undergoes acid catalyzed electrophilic cyclization to give indole 4 . Alternatively, metal carbene $\mathbf{A}$ is trapped by $\beta$ enaminoester 6 to give 14, which further cyclizes under acidic conditions to give the pyrrole 7 .

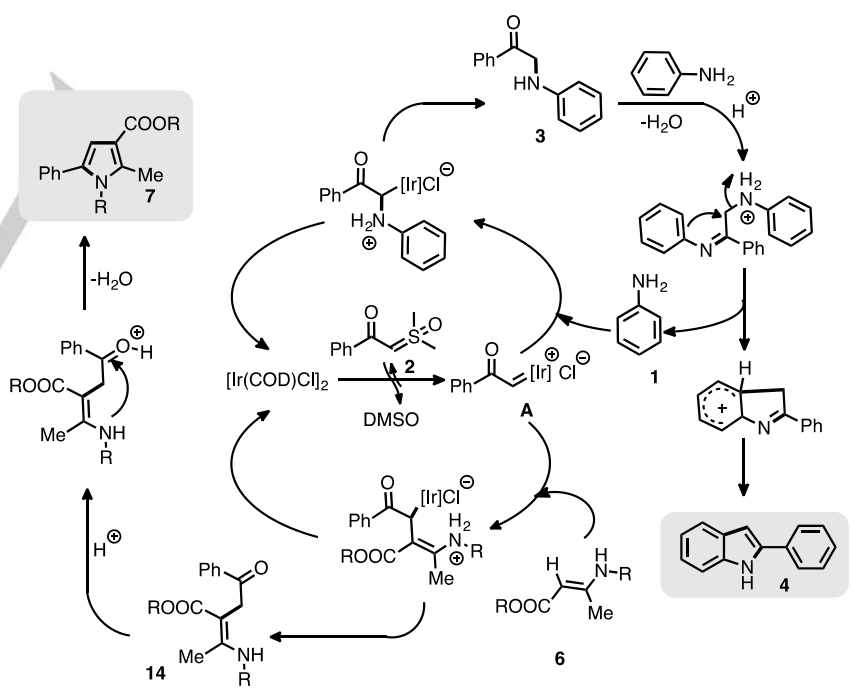

Scheme 8. Plausible mechanism for indole and pyrrole synthesis from sulfoxonium ylide.

This method was also applied to the synthesis of a quinoxaline scaffold 17 using o-phenylenediamine and sulfoxonium ylide (Scheme 9). Interestingly, for this transformation, the additional acid catalyst was not required.

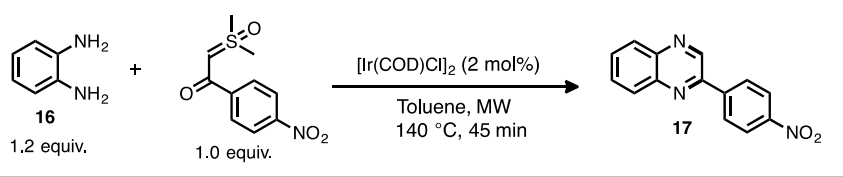


[17] L. Albrecht, L. K. Ransborg, V. Lauridsen, M. Overgaard, T. Zweifel, K. A. Jørgensen, Angew. Chem. Int. Ed. 2011, 50, 12496.

In conclusion, we have demonstrated a novel synthetic strategy for the preparation of indoles (via a cascade involving carbene generation, $\mathrm{N}-\mathrm{H}$ insertion, imine formation, substitution, and aromatization) and pyrroles (via $\mathrm{C}-\mathrm{H}$ insertion of carbenes followed by cyclization) from stable sulfoxonium ylides, employing $[\operatorname{lr}(\mathrm{COD}) \mathrm{Cl}]_{2}$ and $p$-TSA as catalysts. The new approach is operationally straightforward and allows for the synthesis of a range of substituted pyrroles and indoles from easily accessible starting materials and commercially available catalysts.

Keywords: Metal carbenes • Sulfur ylides • Indoles • Pyrroles • Heterocycles

[1] a) A.-H. Li, L.-X. Dai, V. K. Aggarwal, Chem. Rev. 1997, 97, 2341; b) V. K. Aggarwal, C. L. Winn, Acc. Chem. Res. 2004, 37, 611; c) J.-R. Chen X.-Q. Hu, L.-Q. Lu, W.-J. Xiao, Chem. Rev. 2015, 115, 5301.

[2] a) T.-R. Li, F. Tan, L.-Q. Lu, Y. Wei, Y.-N. Wang, Y.-Y. Liu, Q.-Q. Yang, J.-R. Chen, D.-Q. Shi, W.-J. Xiao, Nat. Commun. 2014, 5, 5500; b) Q. Wang, X. Qi, L.-Q. Lu, T.-R. Li, Z.-G. Yuan, K. Zhang, B.-J. Li, Y. Lan, W.-J. Xiao, Angew. Chem. Int. Ed. 2016, 55, 2840; c) J.-R. Chen, W.-R Dong, M. Candy, F.-F. Pan, M. Jörres, C. Bolm, J. Am. Chem. Soc. 2012 134, 6924; d) S. Klimczyk, A. Misale, X. Huang, N. Maulide, Angew. Chem. Int. Ed. 2015, 54, 10365; e) S. Kramer, T. Skrydstrup, Angew Chem. Int. Ed. 2012, 51, 4681; f) V. K. Aggarwal, J. G. Ford, S Fonquerna, H. Adams, R. V. H. Jones, R. Fieldhouse, J. Am. Chem. Soc 1998, 120, 8328; g) X. Huang, S. Klimczyk, L. F. Veiros, N. Maulide, Chem. Sci. 2013, 4, 1105; h) V. K. Aggarwal, J. G. Ford, A. Thompson, R. V. H. Jones, M. C. H. Standen, J. Am. Chem. Soc. 1996, 118, 7004; i) X. Huang, B. Peng, M. Luparia, L. F. R. Gomes, L. F. Veiros, N. Maulide, Angew. Chem. Int. Ed. 2012, 51, 8886; j) J. Sabbatani, X. Huang, L. F. Veiros, N. Maulide, Chem. Eur. J. 2014, 20, 10636; k) S Klimczyk, X. Huang, H. Kahlig, L. F. Veiros, N. Maulide, J. Org. Chem. 2015, 80, 5719.

[3] a) E. J. Corey, M. Chaykovsky, J. Am. Chem. Soc. 1964, 86, 1640; b) B. M. Trost, J. Am. Chem. Soc. 1966, 88, 1587.

[4] M. Gandelman, B. Rybtchinski, N. Ashkenazi, R. M. Gauvin, D. Milstein, J. Am. Chem. Soc. 2001, 123, 5372.

[5] a) J. E. Baldwin, R. M. Adlington, C. R. A. Godfrey, D. W. Gollins, J. G. Vaughan, J. Chem. Soc., Chem. Commun. 1993, 1434; b) I. K. Mangion, I. K. Nwamba, M. Shevlin, M. A. Huffman, Org. Lett. 2009, 11, 3566; c) I. K. Mangion, M. Weisel, Tetrahedron Lett. 2010, 51, 5490; d) A. M. Phelps, V. S. Chan, J. G. Napolitano, S. W. Krabbe, J. M. Schomaker, S. Shekhar, J. Org. Chem. 2016, 81, 4158; e) A. C. B. Burtoloso, R. M. P. Dias, I. A. Leonarczyk, Eur. J. Org. Chem. 2013, 2013, 5005

[6] C. Molinaro, P. G. Bulger, E. E. Lee, B. Kosjek, S. Lau, D. Gauvreau, M. E. Howard, D. J. Wallace, P. D. O'Shea, J. Org. Chem. 2012, 77, 2299.

[7] a) J. A. Moore, D. E. Ree, Org. Synth. 1961, 41, 16; b) M. M. Bio, G. Javadi, Z. J. Song, Synthesis 2005, 19; c) L. D. Proctor, A. J. Warr, Org Process Res. Dev. 2002, 6, 884.

[8] M. Jia, S. Ma, Angew. Chem. Int. Edl. 2016, 55, 9134.

[9] a) T. Kawasaki, K. Higuchi, Nat. Prod. Rep. 2005, 22, 761; b) A. J. Kochanowska-Karamyan, M. T. Hamann, Chem. Rev. 2010, 110, 4489; c) S. Lal, T. J. Snape, Curr. Med. Chem. 2012, 19, 4828.

[10] a) G. R. Humphrey, J. T. Kuethe, Chem. Rev. 2006, 106, 2875; b) D. F. Taber, P. K. Tirunahari, Tetrahedron 2011, 67, 7195.

[11] Q.-Q. Yang, C. Xiao, L.-Q. Lu, J. An, F. Tan, B.-J. Li, W.-J. Xiao, Angew. Chem. Int. Ed. 2012, 51, 9137.

[12] R. Möhlau, Ber. Dtsch. Chem. Ges. 1881, 14, 171.

[13] a) Y. Vara, E. Aldaba, A. Arrieta, J. L. Pizarro, M. I. Arriortua, F. P. Cossio, Org. Biomol. Chem. 2008, 6, 1763; b) V. Sridharan, S. Perumal, C. Avendaño, J. C. Menéndez, Synlett 2006, 2006, 0091.

[14] H. Meier, K.-P. Zeller, Angew. Chem. Int. Ed. 1975, 14, 32

[15] a) K. Pchalek, A. W. Jones, M. M. T. Wekking, D. S. Black, Tetrahedron 2005, 61, 77; b) H. Galons, J.-F. Girardeau, C. C. Farnoux, M. Miocque, J. Heterocycl. Chem. 1981, 18, 561.

[16] For details, see the Supporting Information.

[18] a) H. Fan, J. Peng, M. T. Hamann, J.-F. Hu, Chem. Rev. 2008, 108, 264 b) A. Fürstner, Angew. Chem. Int. Ed. 2003, 42, 3582

[19] A. P. Lea, D. McTavish, Drugs 1997, 53, 828.

[20] a) T. J. Donohoe, N. J. Race, J. F. Bower, C. K. A. Callens, Org. Lett. 2010, 12, 4094; b) P. Mathew, C. V. Asokan, Tetrahedron 2006, 62 1708.

[21] M. N. Eberlin, C. Kascheres, J. Org. Chem. 1988, 53, 2084. 
Entry for the Table of Contents (Please choose one layout)

Layout 2:

\section{COMMUNICATION}

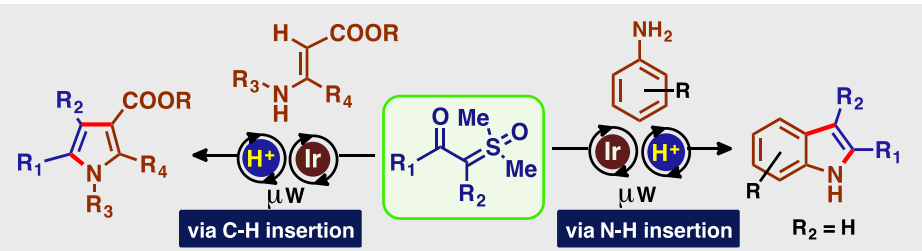

Metal-carbenoids: A one-step protocol for quick assembly of substituted indoles and pyrroles from sulfoxonium ylides and unmodified anilines or easily accesible enamines is described. The method applies tandem catalysis by $[\mathrm{Ir}(\mathrm{cod}) \mathrm{Cl}]_{2}$ and a Brønsted acid under microwave irradiation. Key steps are the formation of iridiumcarbene complexes from sulfoxonium ylides and an unprecedented $\mathrm{C}-\mathrm{H}$ functionalization. The current method is applied to the synthesis of the densely functionalized pyrrole subunit of Atorvastatin.
Janakiram Vaitla, ${ }^{*}$ Annette Bayer, Kathrin H. Hopmann

Page No. - Page No.

Synthesis of Indoles and Pyrroles Utilizing Iridium Carbenes Generated from Sulfoxonium Ylides 